\title{
As indústrias da transformação são concentradas espacialmente? Um teste empírico para o Brasil (2002-2014)
}

Are manufacturing industry spatially concentrated? An empirical test for Brazil (2002-2014)

\begin{abstract}
The article presents new evidence of industrial concentration in Brazil for the period from 2002 to 2014. Based on Ellison and Glaeser (1994, 1997) and using the microdata of the RAIS-ME establishments, it is verified which manufacturing industries are concentrated through two statistical tests. The analysis is disaggregated by sector, and the dynamics of the concentration indicator is explored. The results indicated that industries are more concentrated than they would be if the firms' locational choices were random. And that most industries tended to deconcentrate or the EGI was relatively stable, with the exception of the industry Equipment/Electronic Material, intensive in technology. However, a traditional labor-intensive "Leather Industry" was among the first placed in the EGI ranking, indicating that the labor pooling is an important agglomeration economy to the industry.
\end{abstract}

\section{Keywords}

geography concentration, industry, EllisonGlaeser Index, localization test.

JEL Codes L60, R12.

\author{
Roberta de Moraes Rocha(1) \\ José Ewerton Silva Araujo (2) \\ Edilberto Tiago de Almeida ${ }^{(3)}$ \\ (1) Universidade Federal de Pernambuco \\ (2) Universidade Federal de Pernambuco \\ (3) Universidade Federal de Pernambuco
}

\section{Resumo}

$O$ artigo apresenta novas evidências da concentração industrial no Brasil para o período de 2002 a 2014. A partir de Ellison e Glaeser (1994; 1997) e usando os microdados dos estabelecimentos da RAIS-ME, por meio de dois testes estatísticos, verificam-se quais divisões da indústria da transformação são concentradas. A análise é desagregada setorialmente, e explora-se a dinâmica do indicador de concentração (EGI). Os resultados indicaram que as indústrias são mais concentradas do que seriam se as escolhas locacionais das firmas fossem aleatórias, e que a maioria das indústrias tenderam a se desconcentrar ou o EGI ficou relativamente estável, à exceção da indústria de "Equipamentos/Material Eletrônico", que é de alta tecnologia. Porém, a tradicional "indústria de Artefatos de Couro", intensiva em mão de obra, também esteve entre as primeiras colocadas no ranking do EGI, sugerindo que o labor pooling, entre outros fatores, é uma importante economia de aglomeração da indústria.

\section{Palavras-chave}

concentração geográfica, indústria transformação, indice de Ellison-Glaeser, teste de concentração.

Códigos JEL L60, R12. 


\section{Introdução}

As evidências empíricas para o Brasil (Pacheco, 1999; Diniz; Crocco, 1996; Lautert; Araújo, 2007; Almeida; Rocha, 2018) e demais países (Ellison; Glaeser, 1997; Lu; Tao, 2009; Maurel; Sédillot, 1999) indicam que a atividade produtiva tende a se aglomerar no espaço, mas com diferenças significativas entre os tipos de indústrias. No Brasil, ${ }^{1}$ em torno de $50 \%$ do emprego formal da indústria da transformação, no ano de 2014, localizava-se na segunda menor região do país, na região Sudeste, que ocupa 1/10 do território nacional. E, quase a metade dos trabalhadores formais da indústria da transformação está concentrada nas Regiões Metropolitanas do país.

Naturalmente, ${ }^{2}$ em uma fase mais incipiente da industrialização de um país, e considerando um país típico como o Brasil, composto por regiões com diferentes características geográficas e climáticas, espera-se que a indústria se desenvolva em função das suas vantagens naturais. Mas, com o desenvolvimento dos centros urbanos e de uma razoável infraestrutura de transporte, outros fatores locais, como um melhor acesso ao mercado, devem atuar na atração das indústrias, levando a sua concentração nas grandes cidades. No Brasil, essa fase da industrialização compreendeu os anos de 1940 até a década de 60 (Diniz; Crocco, 1996). Esse período também foi caracterizado por um significante fluxo migratório da população da região Nordeste para a região Sudeste do país, centro econômico do país (Pacheco, 1999). Há relatos de que o fim dessa fase coincidiu com o período de elevado crescimento do país, conhecido como "milagre econômico" (Pacheco, 1999; Diniz; Crocco, 1996).

Da década de 1970 a meados dos anos de 1990, com o adensamento populacional nas grandes cidades, os custos de operação das grandes indústrias começaram a não mais compensar os benefícios obtidos, especialmente, aqueles advindos de um melhor acesso ao mercado (Pacheco, 1999). As evidências indicam que, nesse período, as cidades médias, em especial do estado de São Paulo, começaram a ser percebidas como localidades estratégicas para as indústrias se instalarem, pois não apresentavam custos produtivos tão elevados quanto os grandes centros urbanos, e ainda possuíam vantagens locacionais próximas a eles (Pacheco, 1999; Diniz,

1 Com base na Relação de Informações Sociais do Ministério da Economia (RAIS-ME).

2 Pacheco (1999) faz uma análise mais detalhada destas fases do desenvolvimento do Brasil. 
1993; Diniz; Crocco, 1996). Essa fase também é caracterizada pelas políticas de incentivos à industrialização das regiões Norte e Nordeste do país e deve ter influenciado, ao menos em parte, esse processo de redistribuição da produção industrial (Pacheco, 1999; Lautert; Araújo, 2007).

Ao se esgotar esse modelo de desenvolvimento regional na década de 1990 (Diniz, 1993), que também coincidiu com a abertura comercial do país e com uma crescente guerra fiscal entre as unidades da federação do país (Brito et al., 2009), a indústria brasileira passou por uma nova reestruturação, o que culminou em uma nova fase da industrialização do país (Pacheco, 1999).

Essas evidências são de grande importância para se entender o processo de industrialização mais recente do país, porém dada as limitações de dados na época, os estudos sobre a concentração industrial baseavam-se em dados agregados para a indústria, utilizando quase sempre informações da participação das regiões no emprego e na produção industrial. Por outro lado, quando o objetivo de estudo é analisar, em especial, o grau de concentração setorial, Ellison e Glaeser (1994) argumentam que indicadores baseados nas participações relativas no emprego devem ser utilizados com cautela, já que um setor pode aparentar-se concentrado pelo simples fato de possuir poucas indústrias de grande porte. Nesse caso, o setor, na concepção dos autores, não deve ser considerado concentrado.

Com base nesse argumento e respaldando-se em um modelo de escolha locacional discreta, Ellison e Glaeser (1994) propõem um índice (EGI) para medir o nível da concentração setorial. Em resumo, assume-se que sendo os agentes produtivos racionais - as escolhas locacionais são em função da maximização de seus lucros -, se há uma tendência para um determinado setor se concentrar espacialmente, é porque há vantagens locais que tornam as firmas aglomeradas mais produtivas. Através desse modelo, os autores demostram que na presença de vantagens locacionais - decorrente de um melhor acesso a recursos naturais e de spillovers tecnológicos -, que tornam as firmas mais produtivas, o nível de concentração observado será maior do que aquele esperado se as escolhas locacionais fossem aleatórias. Nesse caso, quando esse resultado é valido para um determinado setor, conclui-se que ele é concentrado.

A fim de contribuir com essa agenda de pesquisa para o Brasil, com base em Ellison e Glaeser (1994; 1997), identifica-se quais indústrias da transformação são concentradas no país, explorando tanto as principais mudanças 
na geografia da distribuição espacial do emprego industrial quanto os resultados por divisão de atividades, daquelas com os mais elevados índices de concentração. Para tanto, calcula-se o EGI, a partir do qual verifica-se através de dois testes estatísticos, um com base num modelo econométrico, se as indústrias da transformação são concentradas no país. Os índices de concentração (EGI) são calculados para cada uma das divisões de atividades da indústria da transformação a 2-dígitos segundo a CNAE-95 (Classificação Nacional de Atividades Econômicas). A unidade geográfica de análise são as microrregiões, o período temporal contempla os anos de 2002 a 2014, e utilizam-se, como principal fonte de dados, os microdados dos estabelecimentos da Relação Anual de Estatísticas Sociais do Ministério da Economia (RAIS-ME), ${ }^{3}$ que abrange todos os estabelecimentos formais do país.

O estudo traz importantes contribuições à literatura nacional aqui citada, ao se basear em um indicador de concentração que tem respaldo em um modelo teórico. E, busca-se dar mais robustez aos resultados através de testes estatísticos sugeridos por Ellison e Glaeser (1994). Além disso, apresentam-se novas evidências da concentração industrial no Brasil, ao explorar a dinâmica dos resultados temporalmente, e por desagregá-los para as divisões de atividades. Esta análise é importante porque as indústrias se diferenciam em função dos seus principais fatores de produção e intensidade tecnológica, entre outros, de modo que as vantagens locacionais ofertadas pelas regiões devem atrair de forma diferente os tipos de indústrias. Assim, consequentemente, tais atributos podem influenciar assimetricamente a distribuição espacial desse setor (Rocha et al., 2013).

\section{Modelo de escolha locacional}

Para se estudar a distribuição da atividade produtiva no espaço, é de extrema importância: fazer um prévio diagnóstico de quais setores realmente podem ser vistos como concentrados; verificar se há diferenças entre o nível de concentração dos setores; e identificar quais fatores explicam os

3 A base de dados utilizada na pesquisa apenas capta informações de empresas formais, porém é a única que disponibiliza informações no nível das empresas para o período de tempo que foi considerado na pesquisa. Porém, segundo estimativas da FIESP, a taxa de formalidade do setor é em torno de $87 \%$, quase o dobro da registrada para a Agropecuária, que é $45 \%$. Para mais informações, consultar: <http://www.fiesp.com.br/indices-pesquisas-e-publicacoes/panorama-da-industria-de-transformacao-brasileira/>. 
diferentes padrões de concentração observados. Nesse sentido, Ellison e Glaeser (1994) propõem um índice de concentração que tem respaldo em um modelo de escolha discreta, e apresenta a vantagem de ser um índice a partir do qual é possível inferir se um setor é mais concentrado do que seria se as escolhas das suas firmas fossem aleatórias. Portanto, se a hipótese de aleatoriedade for rejeitada, o nível de concentração computado através do EGI, que será definido mais adiante, representaria um excesso de aglomeração setorial, e o setor é considerado "concentrado".

De um modo geral, considera-se que uma indústria $j$ - no caso da presente análise empírica, uma divisão de atividades da indústria da transformação, ${ }^{4}$ - possui $N$ estabelecimentos $\operatorname{com} z_{1}, z_{2}, \ldots, z_{n}$ participações no emprego de $i\left(\sum_{n=1}^{N} z_{n}=1\right)$. E o espaço geográfico é dividido em $i$ sub-regiões, aqui representado pelas microrregiões, que têm $x_{1}, x_{2}, \ldots, x_{m}$ participações no emprego nacional $\left(\sum_{i=1}^{M} x_{i}=1\right)$.

A partir da abordagem dos modelos de escolha locacional discreta (McFadden, 1974), Ellison e Glaeser (1997) assumem que se a firma $n$ escolhe a localidade $i$ para se instalar é porque o lucro obtido por $n$ em $i\left(\pi_{n i}\right)$ é maior do que o lucro que poderia ser obtido em qualquer outra localidade.

No modelo completo de Ellison e Glaeser (1997), $\pi_{n i}$ é função do lucro médio recebido pelas firmas em $i\left(\bar{\pi}_{i}\right)$, que depende das características locais de $i$, e dos spillovers tecnológicos gerados pelas firmas já instaladas $\operatorname{em~} i\left(\varphi_{i}\right)$ :

$$
\log \pi_{n i}=\log \bar{\pi}_{i}+\varphi_{i}\left(v_{i}, \ldots, v_{n-1}\right)+\epsilon_{n i}
$$

$v_{i}$ é a sub-região que a firma $n$ escolheu para se instalar e $\epsilon_{n i}$ é o termo de erro aleatório.

Quando $\epsilon_{n i}$ é independente e identicamente distribuído com distribuição Weibull, a probabilidade de $v_{i}$ ser escolhida é:

$$
\operatorname{Prob}\left[v_{i}\right]=p_{i}=\frac{\bar{\pi}_{i}}{\sum_{j} \pi_{j}}
$$

No modelo de escolha aleatória, as escolhas locacionais das firmas não são influenciadas por fatores locais, tais como os recursos naturais e os 4 No texto, por vezes, o termo "indústria" se refere a uma divisão de atividades da indústria da transformação (CNAE-2 dígitos). 
spillovers tecnológicos. Nesse caso, da equação (1), $\varphi_{i}=0$ e ni $=x_{i}$, levando o lucro médio obtido pelas firmas do mesmo setor a depender apenas do tamanho da indústria. Considerando, portanto, que os recursos naturais são distribuídos simetricamente entre as sub-regiões, ou que tais fatores não influenciam a produtividade das firmas, assim como, os spillovers tecnológicos, a relação em (2) pode ser reescrita na forma:

$$
\operatorname{Prob}\left[v_{i}\right]=\frac{x_{i}}{\sum_{j} x_{j}}=x_{i}
$$

A relação (3) indica que, sendo as escolhas locacionais das firmas aleatórias, a probabilidade de $v_{i}$ ser escolhida $\left(p_{i}\right)$ dependerá apenas do tamanho do setor industrial de $v_{i}$, dado que $p_{i}=x_{i}$.

Esse resultado é de extrema importância para as deduções do modelo de escolha locacional aleatória de Ellison e Glaeser (1994; 1997), a partir do qual definem duas métricas que compõem o índice de concentração. O índice de concentração bruta $(g)^{5}$ :

$$
g=\frac{\sum_{i}\left(s_{i}-x_{i}\right)^{2}}{1-\sum_{i} x_{i}^{2}}=\frac{G}{1-\sum_{i} x_{i}^{2}}
$$

$s_{i}=\sum_{n=1}^{N} z_{n} u_{j i}\left(u_{j i}\right.$ é igual a um se $i$ é escolhido por $\left.j\right)$ quantifica a participação de cada sub-região $i$ no emprego de $j$. E, o índice de $\operatorname{Herfindahl~}(\mathrm{H})$ :

$$
H=\sum_{j=1}^{n} z_{j}^{2}
$$

H é uma medida da distribuição do tamanho das plantas/estabelecimentos industriais.

Ellison e Glaeser (1994) demostram pela proposição $1^{6}$ que, se as escolhas locacionais das firmas de um determinado setor forem aleatórias, o valor esperado do índice de concentração bruta será igual ao índice de Herfindahl:

5 De um modo geral, uma primeira medida para avaliar o grau da dispersão da distribuição do emprego da indústria $j$ em torno da sua média é a variância de $s_{i}: \operatorname{var}\left(s_{i}\right)=E\left(s_{i}^{2}\right)-\left(E\left(s_{i}\right)\right)^{2}$. Mas, Ellison e Glaeser (1994) assumem que a participação da localidade $i$ no emprego industrial nacional $\left(x_{i}\right)$ é uma boa aproximação do valor esperado de $s_{i}$, já que outras medidas também se baseiam em $x_{i}$, como o GINI locacional, o que facilita possíveis comparações entre as medidas.

6 Para a demonstração das proposições, ver Ellison e Glaeser (1994). 


$$
E(g)=H
$$

Com a variância $g$ dada por $\operatorname{Var}(g)=\frac{2}{\left(1-\sum_{i} x_{i}^{2}\right)^{2}}\left\{H^{2}\left(\sum x_{i}^{2}-2 \sum x_{i}^{3}+\right.\right.$ $\left.+\left(\sum x_{i}^{2}\right)^{2}\right)-\sum_{j} z_{j}^{4}\left(\sum x_{i}^{2}-4 \sum x_{i}^{3}+3\left(\sum x_{i}^{2}\right)^{2}\right\}$, proposição 2 .

Assim, se as escolhas locacionais dos $n$ estabelecimentos do setor $j$ forem aleatórias, $E(g)=H$. Para dar uma intuição desse resultado, os autores consideram dois casos limites. Quando $H$ é muito pequeno, o que significa dizer que o setor $j$ é composto por uma quantidade grande de pequenas firmas, aproximando-se de um mercado sob concorrência perfeita, $H$ tenderá a zero, e como $s_{i}$ se aproximará de $x_{j}, g$ também tenderá a zero. E, no outro caso limite, quando o espaço geográfico é composto por infinitas sub-regiões, de modo que $x_{i}$ seja muito pequeno, próximo de zero, então $\left(s_{i}-x_{i}\right)^{2}$ se reduzirá a $\left(s_{i}\right)^{2}$, que é igual a $\left(\sum_{i} z_{j} u_{i i}\right)^{2} \operatorname{com} u_{k i}=1$ se $i$ é escolhida (0 no caso contrário).

Ellison e Glaeser (1994) modificam o modelo de escolha aleatória, ao considerar que $\left(\bar{\pi}_{i}\right)$ também é influenciado pelos recursos naturais das sub-regiões, e definem um parâmetro que capta as vantagens produtivas advindas das vantagens naturais $\left(\gamma_{0}\right)$, que varia entre 0 e 1 . Ao assumir que o $\left(\bar{\pi}_{i}\right)$ tem uma distribuição tal que $E\left(p_{i}\right)=x_{i}$ e a $\operatorname{var}\left(p_{i}\right)=\gamma_{0} x_{i}\left(1-x_{i}\right)$, os autores demostram, pela proposição 3 , que:

$$
E(g)=\gamma_{0}+\left(1-\gamma_{0}\right) H
$$

No caso particular de $\gamma_{0}=0$, tem-se o mesmo resultado do modelo de escolha aleatória, $E(g)=H$.

No Modelo de Spillovers Tecnológicos, as escolhas locacionais das firmas são realizadas de acordo com as prévias escolhas das firmas já instaladas nas sub-regiões, como em um modelo de expectativas racionais. Assume-se, portanto, que $u_{n^{\prime} i}$ e $u_{n^{\prime \prime}}$ ão variáveis aleatórias não independentes com distribuição de Bernoulli, e as escolhas locacionais de quaisquer duas firmas são correlacionadas, $\operatorname{cor}\left(u_{n^{\prime} i} u_{n^{\prime} i}\right)=\gamma_{0}$. Nesse modelo, o parâmetro $\gamma_{0}$ é uma medida que capta a importância dos spillovers tecnológicos para explicar as escolhas locacionais das firmas do setor $j$. Quando $E\left(u_{n^{\prime} i} u_{n^{\prime \prime}}\right)=\gamma_{0} p_{i}+\left(1-\gamma_{0}\right) p_{i}^{2}$, Ellison e Glaeser (1994) novamente demostram, pela proposição 4 , que: 


$$
E(g)=\gamma_{0}+\left(1-\gamma_{0}\right) H
$$

De (7), se as escolhas locacionais das firmas não forem correlacionadas, $\gamma_{0}=0$ e $E(g)=H$.

Percebe-se que tanto no modelo de vantagens naturais, quanto no modelo de spillovers tecnológicos, quanto mais $E(g)$ diferir de $H$, maior deve ser as forças que atuam a favor da aglomeração das indústrias do setor $j$.

Com base nestes resultados, Ellison e Glaeser (1994; 1997) propõem um novo índice para medir o nível de concentração industrial (EGI):

$$
E G I=\gamma \equiv \frac{g-H}{1-H}
$$

O EGI é interpretado como o índice de concentração bruta do setor $j(g)$ ponderado pela distribuição do tamanho das indústrias de um dado setor $(H)$. Assim, o EGI é um estimador não-viesado do parâmetro $\gamma_{0}$, que capta vantagens produtivas geradas pelos recursos naturais e spillovers tecnológicos: Assim, valores positivos do EGI indicam que o setor em estudo é mais aglomerado do que seria se as escolhas locacionais das indústrias pertencentes a ele fossem aleatórias. Percebe-se, ainda, que pela expressão (8) é possível obter valores negativos para o EGI, compatíveis com os setores que têm uma distribuição próxima ao setor industrial agregado e ainda com uma participação de grandes plantas industriais.

Conforme Ellison e Glaeser (1994) destacam, o EGI apresenta a vantagem de ser um estimador não viesado do parâmetro que quantifica as economias de aglomeração no modelo de vantagens naturais e no modelo de spillovers tecnológicos. Além disso, o EGI é ponderado pela influência da distribuição do tamanho das indústrias e das unidades geográficas.

Porém, reconhece-se que o EGI, por ser um índice discreto, é menos informativo do que os índices baseados em distância, quando o interesse de análise é, além de verificar se os setores são concentrados ou não, identificar as diferenças entre o raio espacial que a concentração é observada. Contudo, ainda não se tem conhecimento da existência de uma base de dados para o Brasil que disponibilize informações das coordenadas geográficas para todas as indústrias do país, o que ainda inviabiliza o cálculo desses índices a uma escala nacional. 


\section{Dados}

A base de dados utilizada para o cálculo do índice de Ellison e Glaeser (1994) é composta por todos os estabelecimentos formais do país que têm registro na Relação Anual de Informações Sociais (RAIS) do Ministério da Economia (ME). Para o Brasil, está é a única fonte de dados que disponibiliza informações, para pesquisas acadêmicas, no nível dos estabelecimentos, para uma série longa de tempo, desagregada segundo a CNAE a 4 dígitos. Porém, reconhece-se que a magnitude do tamanho do setor industrial pode ser subestimada ao considerar-se apenas as empresas formais. O período de análise compreende os anos de 2002 a 2014, para os quais teve-se acesso aos dados. ${ }^{8} \mathrm{O}$ estudo é desagregado por divisões da indústria da transformação (CNAE 95-2 dígitos). ${ }^{9}$ Porém, como há uma descontinuidade da classificação CNAE 95 para a divisão da indústria de Fabricação de Coque, Refino de Petróleo, Elaboração de Combustíveis Nucleares e Produção de Álcool (DIVISÃO 23), tal indústria foi retirada do estudo. ${ }^{10}$

A unidade geográfica de referência para o estudo é composta pelas microrregiões, considerando que para um nível mais desagregado haveria muitos " $s$ " iguais a zero, o que comprometeria a análise. E, para um nível mais agregado espacialmente, como as unidades da federação, acredita-se que haveria perda de informação, já que são muito heterogêneas, com diferenças significantes entre a distribuição das indústrias dentro do estado. Ademais, a definição de microrregião, de acordo com o IBGE, ${ }^{11}$ leva em consideração as especificidades e semelhanças das características produtivas dos municípios que as integram, o que torna essa unidade geográfica importante para estudos sobre concentração industrial.

8 Como a base utilizada na pesquisa não é pública e foi disponibilizada segundo termo de compromisso de sigilo aos dados, o seu acesso tem um desfasamento de tempo, por isso o último ano de análise foi 2014.

9 A escolha da CNAE 95, em detrimento da CNAE 2.0 (utilizada pelo RAIS-ME a partir de 2006), deveu-se ao fato de essa classificação estar disponível para um período de tempo mais longo (incluindo o último ano da análise, 2014), o que facilita comparações com outros estudos e futuras extensões deste estudo.

10 A partir do ano de 2006 o Ministério da Economia adotou a CNAE 2.0, porém continuou divulgando os dados da RAIS segundo a CNAE 95.

11 Para mais informações sobre a divisão política-administrativa do país, consultar: $<$ http:// www.ngb.ibge.gov.br/Default.aspx?pagina $=$ divisao $>$. 


\section{Concentração industrial a partir do índice de Ellison e Glaeser}

Na literatura da Ciência Regional, a análise em torno da concentração dos agentes produtivos no espaço e os ganhos de produtividade gerados por fatores exógenos a firma - que de certo modo pode explicar as disparidades regionais de crescimento - não é recente, e foi documentada pioneiramente por Marshall (1890), Myrdal (1957), Hirschman (1958), entre outros. A partir desses estudos, autores como Krugman (1991), precursor da "Nova Geografia Econômica", e Venables (1996), Fujita e Thisse (2002), Ellison e Glaeser (1997), vieram a contribuir para a formalização de modelos e indicadores de concentração, dando mais rigor analítico aos estudos sobre localização da atividade produtiva e economias de aglomeração. Porém, apenas na década de 1990, período também que os dados se tornaram mais acessíveis no Brasil, avanços vêm sendo realizados na literatura nacional sobre essa temática de estudo. Associado a esse fato, com a consolidação de alguns Arranjos Produtivos no país (APLs) ${ }^{12}$ no país, especialmente a partir dos anos de 1990, o tema tornou-se objeto de análise tanto de acadêmicos, quando dos gestores públicos. ${ }^{13}$ Contudo, a fim de tecer comparações com os resultados aqui analisados, a análise a seguir restringe-se aos estudos que utilizaram o índice de Ellison e Glaeser (1997).

Com base em alguns resultados já obtidos para o Brasil, que aplicam o EGI para analisar a concentração industrial no país, é possível fazer duas principais constatações (Resende; Willey, 2005 Lautert; Araújo, 2007; Vignandi et al., 2014; Costa; Biderman, 2016): a) que a maioria das divisões da indústria da transformação no país tende a ser concentrada; e b) que há uma tendência no país para uma desconcentração, pelo menos com suporte empírico até a década de 2000.

Resende e Willey (2004), a partir de três medidas de concentração - o índice de Ellison e Glaeser (1997), o índice de Maurel e Sédillot (1999) e o índice de Devereux et al. (2004) - medem o grau da concentração da indústria da transformação no Brasil entre 1995 e 2001. Os autores constatam

12 O termo "Arranjo Produtivo Local", segundo definição da REDESIST, é atribuído a "aglomerações territoriais de agentes econômicos, políticos e sociais - com foco em um conjunto específico de atividades econômicas - que apresentam algum vínculo".

13 Citam-se, por exemplo, as políticas estaduais de incentivos fiscais para as empresas inseridas em APLs. 
que os três índices são correlacionados positivamente e obtêm indicações de que houve redução da concentração da indústria da transformação. Os autores dão uma importante contribuição no campo metodológico ao apresentarem didaticamente os índices de concentração, porém não demonstram consistentemente qual índice seria o melhor para a análise, tão pouco exploram os resultados setorialmente.

Com o objetivo de medir o nível de concentração industrial no país, Lautert e Araújo (2007) calculam o EGI para as indústrias da transformação do país, considerando as Unidades da Federação como área geográfica de análise, e constatam que houve uma redução do EGI médio, entre 1996 e 2001. Os autores observam que as indústrias intensivas em tecnologia e as indústrias intensivas em recursos naturais são as que apresentaram os maiores índices.

Com contribuições metodológicas para a mensuração da concentração industrial no país, Vignandi et al. (2014) fazem uma ponderação espacial do EGI para captar a influência do efeito vizinhança no índice. Os autores obtêm indicações, considerando as mesorregiões e divisões de atividade da indústria da transformação, de que a indústria no país tendeu a se desconcentrar entre 1995 e 2010.

Outro trabalho que merece destaque é o de Costa e Biderman (2016), que extrapola o objetivo de medir o grau da concentração geográfica da indústria, ao apresentarem evidências das fontes de variação do EGI, com base na decomposição proposta por Dumais, Ellison e Glaeser (2002). Os autores consideram um período que compreende os anos de 1991 a 2011, e utilizam a CNAE 95 como referência para compatibilização das bases. Corroborando os resultados já obtidos para o Brasil, os autores obtêm indicações de que houve uma tendência de desconcentração da indústria no país. E, a decomposição do índice sugere que a abertura de novas empresas em microrregiões médias contribuiu, em maior magnitude, para essa desconcentração.

Dado esse primeiro conjunto de evidências em torno da concentração industrial no Brasil, especialmente até a década de 2000, a presente pesquisa busca contribuir com novas evidências para um período mais recente, de 2002 a 2014. Além disso, buscando agregar evidências às já obtidas para o Brasil, é feita uma análise por divisão de atividades, destacando aquelas que apresentaram resultados que destoaram da média registrada para toda a indústria. 
Antes de proceder aos testes empíricos com base no EGI, a Figura 1 apresenta a distribuição do emprego da indústria no país entre as microrregiões, para o ano de 2002 e o ano de 2014. Uma primeira constatação que se tem ao visualizar as figuras, para ambos os anos, é a expressiva participação das microrregiões do Centro-Sul e do litoral do país no emprego industrial, com destaque para a região Sudeste. Essas evidências, como esperado, deve-se ao fato de essas localidades apresentarem uma melhor infraestrutura tecnológica/transportes e acesso ao mercado consumidor, o que reduz os seus custos de transações. Quanto às principais mudanças na geografia da distribuição do emprego entre os dois anos, destaca-se que foram em direção ao centro do país, especialmente para a região Centro-Oeste. De fato, enquanto todas as grandes regiões do país tiveram perda ou poucas mudanças na sua participação no emprego industrial, a parcela da região Centro-Oeste cresceu em torno de $36 \%$ (passou de $4 \%$ para $6 \%$ ), entre o ano de 2002 e o ano de 2014. Corroborando esses resultados, Costa e Biderman (2016), em um estudo sobre a dinâmica da concentração do emprego industrial no período de 1991 a 2011, concluem, entre os principais resultados, que a região Centro-Oeste foi uma das grandes responsáveis pela desconcentração industrial registrada no país. Apesar da pouca representatividade da região no emprego industrial do país, o Centro-Oeste vem se industrializando até mais tardiamente do que as demais regiões. No ano de 2014, a indústria da transformação já respondia por 11,5 \% do emprego formal da região, um aumento de $15 \%$ em relação ao ano de 2002; enquanto nas demais regiões houve um processo de perda de importância economia da indústria, em relação a geração de emprego. Miragaya (2014) destaca que a industrialização do Centro-Oeste está associada ao crescimento e à modernização da agropecuária na região visando, em especial, o mercado externo. Como resultado desse processo, indústrias que integram a cadeia produtiva do setor agropecuário, como as indústrias de alimentos, lacticínios e a frigorífica, entre outras, se instalaram na região. Além disso, Dinis (2001) evidência o papel das políticas regionais de incentivos fiscais e de construção de infraestrutura, que também contribuíram para a industrialização do Centro-Oeste. Para retratar a importância dessas políticas para o crescimento econômico da região, estimativas de Monteiro Neto e Gomes (2000) indicam que, entre o período de 1960 e 1996, houve anos em que a participação do setor público chegou a representar a metade do PIB da região Centro-Oeste. 
Figura 1 Distribuição espacial da participação relativa do emprego na indústria da transformação por microrregiões do Brasil em 2002 e 2014

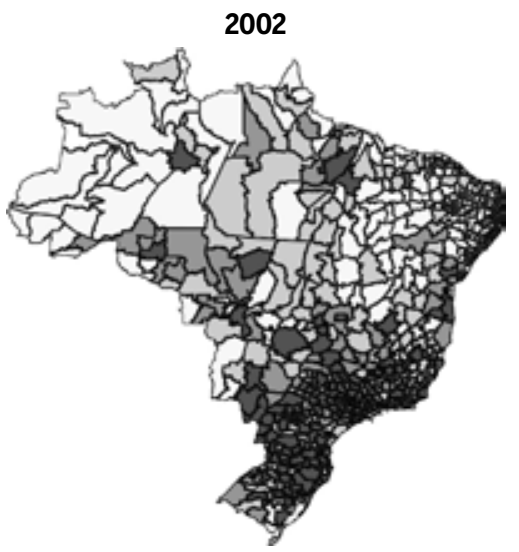

$\square(.001,1]$

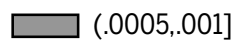

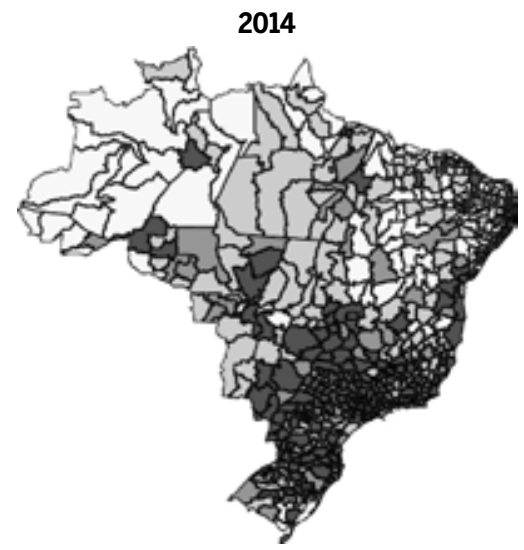

$(.0001, .0005]$
$(0, .0001]$

Fonte: Elaboração própria a partir dos microdados da RAIS-ME (2002-2014).

A análise a seguir baseia-se no cálculo do EGI para as divisões de atividades da indústria da transformação segundo a CNAE 95 (2-dígitos), que corresponde a 22 divisões industriais, excluindo a divisão 23. Nesse sentido, seguindo Ellison e Glaeser (1997), com base nos componentes calculados do EGI, dispostos na Tabela A do Apêndice, é testado se o valor esperado médio de $G$ é igual ao valor observado médio de $G\left[E(G)=\left(1-\sum_{i} x_{i}^{2}\right) H\right]$. Conforme esse teste, se a hipótese nula for rejeitada, deve-se considerar que o setor tem excesso de concentração, em contraposição ao resultado que seria obtido se as escolhas locacionais das indústrias do setor fossem aleatórias. E, nesse caso, o setor deve ser considerado "concentrado".

A Tabela 1 apresenta os resultados dos testes para a indústria da transformação, considerando os resultados médios obtidos para as divisões de atividades. De posse desses resultados, tem-se que o valor observado médio de $G$ é, para todos os anos, significativamente maior que o $E(G)$, com desvio padrão ${ }^{14}$ menor que 0,005 . Esse resultado indica que, em média, a indústria da transformação é mais concentrada do que seria se sua distribuição espacial fosse aleatória.

$14 \operatorname{Var}(G)=2\left\{H^{2}\left(\sum x_{i}^{2}-2 \sum x_{i}^{3}+\left(\sum x_{i}^{2}\right)^{2}\right)-\sum_{j} z_{j}^{4}\left(\sum x_{i}^{2}-4 \sum x_{i}^{3}+3\left(\sum x_{i}^{2}\right)^{2}\right)\right\}$ 
O teste realizado para cada uma das divisões de atividades também rejeita a hipótese de aleatoriedade, indicando que todas as divisões são concentradas. Ellison e Glaeser (1997) encontram resultados semelhantes para as indústrias da transformação dos Estados Unidos; 97\% dos setores analisados pelos autores são localizados/concentrados.

Tabela 1 Valor esperado, observado e desvio padrão de G (2002 a 2014)

\begin{tabular}{lrrrrr}
\hline Ano & G médio & $\mathbf{E}(\mathbf{G})$ médio & $\begin{array}{r}\text { Diferença } \\
\text { entre G médio } \\
\text { e E(G) médio }\end{array}$ & $\begin{array}{r}\text { Desvio padrão } \\
\text { médio de G }\end{array}$ \\
\hline 2002 & 0,0318 & 0,0070 & 0,0248 & 0,0013 \\
\hline 2003 & 0,0304 & 0,0064 & 0,0240 & 0,0012 \\
\hline 2004 & 0,0303 & 0,0063 & 0,0239 & 0,0012 \\
\hline 2005 & 0,0298 & 0,0063 & 0,0234 & 0,0012 \\
\hline 2006 & 0,0282 & 0,0063 & 0,0219 & 0,0012 \\
\hline 2007 & 0,0293 & 0,0064 & 0,0229 & 0,0011 \\
\hline 2009 & 0,0270 & 0,0067 & 0,0203 & 0,0012 \\
\hline 2010 & 0,0259 & 0,0063 & 0,0196 & 0,0011 \\
\hline 2011 & 0,0259 & 0,0062 & 0,0197 & 0,0011 \\
\hline 2012 & 0,0261 & 0,0061 & 0,0200 & 0,0011 \\
\hline 2013 & 0,0266 & 0,0061 & 0,0205 & 0,0010 \\
\hline
\end{tabular}

Fonte: Elaboração própria a partir dos microdados da RAIS-ME (2002-2014).

Para dar robustez a esses resultados, conforme sugerido por Ellison e Glaeser (1997), testa-se a hipótese de aleatoriedade $\left[E\left(g_{j}\right)=H_{j}\right]$ com base na estimação da equação $g_{j}=\alpha_{0}+\alpha_{1} H_{j}+\mu_{j}$. De posse dos coeficientes estimados, se a hipótese conjunta de que $\alpha_{0}=0$ e $\alpha_{1}=1$ for aceita, então $\gamma_{0}=0$. Os resultados desse teste encontram-se na Tabela 2 e indicam que as indústrias da transformação não são distribuídas aleatoriamente.

Adicionalmente, a partir da Tabela 3, observa-se que, no período de análise, houve uma tendência do decrescimento do índice médio, indicando que a indústria da transformação está se tornando menos concentrada no país. 
Tabela 2 Teste de aleatoriedade da concentração $(2002,2009,2014)$

\begin{tabular}{lrrrr}
\hline Variável & Coeficiente (2002) & Coeficiente (2009) & Coeficiente (2014) \\
\hline \multirow{2}{*}{ Constante } & $0,017^{*}$ & $0,0109^{*}$ & 0,008 \\
& $(2,37)$ & $(2,36)$ & $(1,51)$ \\
\hline $\mathbf{H}$ & $2,095^{*}$ & $2,427^{*}$ & $2,668^{*}$ \\
& $(4,17)$ & $(6,18)$ & $(5,96)$ \\
\hline F: $\boldsymbol{\alpha}_{\mathbf{0}}=\mathbf{0}$ e $\boldsymbol{\alpha}_{\mathbf{1}} \mathbf{= 1}$ & $21,08^{*}$ & $42,53^{*}$ & $33,73^{*}$ \\
\hline $\mathbf{R}^{\mathbf{2}}$ & 0,46 & 0,65 & 0,63 \\
\hline
\end{tabular}

Fonte: Elaboração própria a partir dos dados da RAIS.

Nota: ${ }^{*}$ Estatisticamente significante a menos de 5\%. Valores entre os parênteses se referem ao erro padrão do coeficiente.

Tabela 3 Estatísticas descritivas do índice de Ellison e Glaeser (1997)

\begin{tabular}{lrrrr}
\hline Ano & Média & Desvio Padrão & Máximo & Mínimo \\
\hline $\mathbf{2 0 0 2}$ & 0,0258 & 0,0342 & 0,1516 & 0,0037 \\
\hline $\mathbf{2 0 0 3}$ & 0,0249 & 0,0320 & 0,1354 & 0,0041 \\
\hline $\mathbf{2 0 0 4}$ & 0,0248 & 0,0314 & 0,1152 & 0,0032 \\
\hline $\mathbf{2 0 0 5}$ & 0,0243 & 0,0325 & 0,1357 & 0,0030 \\
\hline $\mathbf{2 0 0 6}$ & 0,0227 & 0,0285 & 0,1165 & 0,0025 \\
\hline $\mathbf{2 0 0 8}$ & 0,0237 & 0,0285 & 0,1053 & 0,0025 \\
\hline $\mathbf{2 0 0 9}$ & 0,0211 & 0,0247 & 0,0915 & 0,0025 \\
\hline $\mathbf{2 0 1 0}$ & 0,0203 & 0,0233 & 0,0871 & 0,0028 \\
\hline $\mathbf{2 0 1 1}$ & 0,0204 & 0,0256 & 0,0919 & 0,0030 \\
\hline $\mathbf{2 0 1 2}$ & 0,0206 & 0,0282 & 0,1146 & 0,0030 \\
\hline $\mathbf{2 0 1 3}$ & 0,0212 & 0,0299 & 0,1143 & 0,0029 \\
\hline $\mathbf{2 0 1 4}$ & 0,0225 & 0,0332 & 0,1300 & 0,0026 \\
\hline
\end{tabular}

Fonte: Elaboração própria a partir dos dados da RAIS.

Como as indústrias analisadas apresentam uma significante heterogeneidade nos seus níveis de concentração, o que pode ser observado pelo desvio padrão do índice médio, pouco se pode inferir sobre o padrão da dinâmica da concentração ou desconcentração das indústrias a partir da média do EGI. Por isso, os resultados a seguir são desagregados por divisão de atividades. 


\section{Análise setorial}

Ellison e Glaeser (1997) consideram três faixas de valores do EGI para classificar as indústrias quanto à magnitude do nível de concentração: menor do que 0,02 é considerado de baixa concentração $(y<0,02)$; entre $0,02 \mathrm{e}$ 0,05 , concentração moderada $[y \in(0,02-0,05)]$; e maior que 0,05 , concentração elevada $(y>0,05)$.

A Tabela 4 apresenta a média do EGI e o percentual de indústrias nas três faixas de valores definidos por Ellison e Glaeser (1997). Inicialmente, observa-se que o EGI se manteve na faixa de concentração moderada em todo o período de análise, variou entre 0,0203 (ano de 2009) e 0,0258 (ano de 2002), fechando o período em 0,0207 (ano de 2014). Considerando esses intervalos de valores, duas indústrias se mantiveram no nível de alta concentração em todo o período, a indústria de Fumo (divisão 16) e a indústria de Fabricação de Material Eletrônico/Equipamentos de Comunicações (divisão 32). E a maioria das indústrias se manteve em um nível de baixa concentração.

Tabela 4 Níveis de Concentração do EGI das Indústrias no Brasil (2002-2014)

\begin{tabular}{l|rrrrrrrr}
\hline Ano & Média (EGI) & \multicolumn{3}{|c}{$\boldsymbol{y}<\mathbf{0 , 0 2}$} & $\boldsymbol{y} \in \mathbf{( 0 , 0 2}-\mathbf{0 , 0 5})$ & \multicolumn{2}{c}{$\boldsymbol{y}>\mathbf{0 , 0 5}$} \\
\hline $\mathbf{2 0 0 2}$ & 0,0258 & $63,64 \%$ & 14 & $22,73 \%$ & 5 & $13,64 \%$ & 3 \\
\hline $\mathbf{2 0 0 3}$ & 0,0249 & $59,09 \%$ & 13 & $27,27 \%$ & 6 & $13,64 \%$ & 3 \\
\hline $\mathbf{2 0 0 4}$ & 0,0248 & $63,64 \%$ & 14 & $22,73 \%$ & 5 & $13,64 \%$ & 3 \\
\hline $\mathbf{2 0 0 5}$ & 0,0243 & $72,73 \%$ & 16 & $18,18 \%$ & 4 & $9,09 \%$ & 2 \\
\hline $\mathbf{2 0 0 6}$ & 0,0227 & $72,73 \%$ & 16 & $13,64 \%$ & 3 & $13,64 \%$ & 3 \\
\hline $\mathbf{2 0 0 7}$ & 0,0238 & $72,73 \%$ & 16 & $13,64 \%$ & 3 & $13,64 \%$ & 3 \\
\hline $\mathbf{2 0 0 8}$ & 0,0211 & $72,73 \%$ & 16 & $13,64 \%$ & 3 & $13,64 \%$ & 3 \\
\hline $\mathbf{2 0 0 9}$ & 0,0203 & $72,73 \%$ & 16 & $13,64 \%$ & 3 & $13,64 \%$ & 3 \\
\hline $\mathbf{2 0 1 0}$ & 0,0205 & $68,18 \%$ & 15 & $22,73 \%$ & 5 & $9,09 \%$ & 2 \\
\hline $\mathbf{2 0 1 1}$ & 0,0207 & $81,82 \%$ & 18 & $9,09 \%$ & 2 & $9,09 \%$ & 2 \\
\hline $\mathbf{2 0 1 2}$ & 0,0213 & $77,27 \%$ & 17 & $13,64 \%$ & 3 & $9,09 \%$ & 2 \\
\hline $\mathbf{2 0 1 3}$ & 0,0225 & $77,27 \%$ & 17 & $13,64 \%$ & 3 & $9,09 \%$ & 2 \\
\hline $\mathbf{2 0 1 4}$ & 0,0207 & $77,27 \%$ & 17 & $13,64 \%$ & 3 & $9,09 \%$ & 2 \\
\hline
\end{tabular}

Fonte: Elaboração própria a partir de dados da RAIS.

Conforme modelo teórico adotado como base, espera-se que quanto mais concentrada for a indústria mais importante serão os fatores locais, gera- 
dores de economias de aglomeração, para explicar as escolhas locacionais das firmas da indústria. Por esses motivos, a análise a seguir prioriza as que apresentaram os maiores EGI. Porém, reconhece-se que a distribuição geográfica de algumas indústrias no país, em alguma medida, foi influenciada "artificialmente" por políticas de incentivos fiscais. A Tabela 5 apresenta o ranking do EGI calculado para todas as divisões da indústria da transformação, para os anos de 2002, 2009 e 2014. De um modo geral, percebe-se certa estabilidade das indústrias que se mantiveram nas primeiras colocações: Fumo (divisão16); Artigos de Couro (divisão 19); Fabricação de Material Eletrônico/Equipamentos de Comunicações (divisão 32); e a de Fabricação de outros Equipamentos de Transporte (divisão 35). Esses resultados também corroboram os rankings do EGI obtido por Lautert e Araújo (1997) e por Vignandi et al. (2014). Ellison e Glaeser (1997) evidenciam para os Estados Unidos que, entre as indústrias a dois dígitos com um maior percentual de classes de atividade na faixa de alta concentração $(y>0,05)$, estão as indústrias de: Fumo, Têxtil, Produtos de Couro; Petróleo e Gás e Equipamentos de Transporte.

Contudo, de um modo geral, os resultados (Tabela 5) não apontaram regularidade entre a ordenação no ranking e as características produtivas das indústrias - tipo de bem produzido, nível tecnológico, ${ }^{15}$ ou intensidade do fator de produção -, de modo que não foi possível estabelecer generalizações com base na associação entre o nível de concentração e essas características. Porém, cabe fazer algumas considerações quanto às divisões que se mantiveram entre as primeiras colocadas nos rankings. Três delas são do ramo da Fabricação de Produtos Industriais de alta tecnologia: eletrônico/comunicações (divisão 32); veículos automotores (divisão 34) e equipamentos de transporte marítimo, ferroviário e aéreo (divisão 35). Como essas indústrias são intensivas em tecnologia, a proximidade geográfica com indústrias do mesmo setor deve gerar spillovers tecnológicos, entre outros ganhos, como o compartilhamento de infraestrutura, tornando-as mais produtivas quando estão concentradas (Henderson, 2003). Por outro lado, Freitas e Simões (2002) obtêm evidências, para as microrregiões brasileiras, da importância das economias de urbanização para explicar a concentração geográfica das indústrias intensivas em tecnologia, já que estas têm ganhos de produtividades quando instaladas nos centros urba-

15 Consultar a classificação em: <https://ww2.ibge.gov.br/home/estatistica/economia/industria/pia/empresas/comentario2003.pdf>. 
nos. Ressaltam-se, porém, que a localização das três indústrias no país é influenciada, em algum grau, por incentivos fiscais, como será apresentado na próxima seção.

Tabela 5 Ranking do EGI das divisões da indústria da transformação no Brasil (2002, 2009, 2014)

\begin{tabular}{|c|c|c|c|c|c|}
\hline DIV. CNAE & Ranking 02 & DIV. CNAE & Ranking 09 & DIV. CNAE & Ranking 14 \\
\hline 16 & 0,1516 & 16 & 0,0872 & 32 & 0,1111 \\
\hline 32 & 0,0847 & 32 & 0,0720 & 16 & 0,0985 \\
\hline 19 & 0,0613 & 35 & 0,0575 & 35 & 0,0464 \\
\hline 34 & 0,0345 & 19 & 0,0422 & 19 & 0,0379 \\
\hline 35 & 0,0318 & 34 & 0,0228 & 22 & 0,0215 \\
\hline 20 & 0,0255 & 17 & 0,0208 & 30 & 0,0195 \\
\hline 22 & 0,0247 & 22 & 0,0192 & 34 & 0,0192 \\
\hline 30 & 0,0220 & 20 & 0,0174 & 17 & 0,0184 \\
\hline 33 & 0,0183 & 30 & 0,0148 & 20 & 0,0153 \\
\hline 17 & 0,0167 & 24 & 0,0145 & 33 & 0,0105 \\
\hline 24 & 0,0145 & 33 & 0,0139 & 18 & 0,0091 \\
\hline 15 & 0,0099 & 18 & 0,0093 & 36 & 0,0063 \\
\hline 25 & 0,0097 & 15 & 0,0080 & 15 & 0,0059 \\
\hline 31 & 0,0092 & 36 & 0,0070 & 26 & 0,0055 \\
\hline 18 & 0,0087 & 31 & 0,0065 & 25 & 0,0051 \\
\hline 37 & 0,0087 & 25 & 0,0064 & 24 & 0,0048 \\
\hline 29 & 0,0078 & 27 & 0,0061 & 27 & 0,0047 \\
\hline 26 & 0,0078 & 26 & 0,0055 & 31 & 0,0040 \\
\hline 36 & 0,0068 & 37 & 0,0045 & 37 & 0,0035 \\
\hline 27 & 0,0059 & 29 & 0,0043 & 29 & 0,0033 \\
\hline 28 & 0,0053 & 28 & 0,0043 & 21 & 0,0031 \\
\hline 21 & 0,0037 & 21 & 0,0029 & 28 & 0,0026 \\
\hline
\end{tabular}

Fonte: Microdados RAIS-ME.

Entre as indústrias menos concentradas, estão a indústria de Fabricação de Celulose/Produtos de Papel (divisão 21) e a indústria de Fabricação de Produtos de Metal (divisão 28), ambas classificadas pelo IBGE $^{16}$ de média ww2.ibge.gov.br/home/estatistica/economia/industria/pia/empresas/defaultempresa2004. shtm>. 
intensidade tecnológica. As duas indústrias têm características específicas que as diferenciam, mas que podem explicar a sua maior dispersão espacial relativamente às demais indústrias. A indústria de Celulose e Papel produz mais intensamente produtos de bens de consumo não duráveis e de baixo valor agregado, como os produtos de papel, e por isso deve se localizar nas regiões com melhor acesso ao mercado, já que o custo de transporte não compensaria os ganhos de aglomeração possivelmente advindos da interação com outras indústrias da mesma divisão. Enquanto a indústria de Produtos de Metal produz, em especial, estruturas metálicas pesadas e insumos de metal utilizados por outras indústrias. Assim, como a indústria fornece insumos para a maioria das atividades produtivas - que engloba indústrias de Alimentos e Construção Civil - a indústria tende a se instalar próximas aos seus demandantes. No Brasil, país de grande dimensão territorial e com sérios problemas de infraestrutura de transporte, o custo de transporte deve atuar contrabalanceando as forças de aglomeração, conforme sugerido por Krugman (1991).

Destaca-se ainda uma das indústrias mais importantes para o país, a indústria de Alimentos e Bebidas, que no período de análise responderam, em média, por $20 \%$ do emprego formal da indústria da transformação e por $20 \%$ do valor bruto da produção industrial, ${ }^{17}$ manteve-se na faixa de baixa concentração em todos os anos de estudo. No Brasil, essa indústria produz tanto bens de consumo não duráveis, quanto bens intermediários, e é de baixa intensidade tecnológica e intensiva em mão de obra. Dadas essas características e considerando que ela é uma indústria que está diretamente relacionada com o setor de serviços de alojamento e alimentação, ${ }^{18}$ a indústria deve se distribuir em função do acesso ao mercado e de uma logística que otimize a distribuição de seus produtos. Porém, reconhece-se a importância do setor agrícola, que é o principal fornecedor de insumos a indústria, e por isso deve explicar, em parte, a sua distribuição espacial.

A seguir, expande-se a análise para as quatro divisões que apresentaram, em algum dos anos, o índice na faixa de alta concentração. $O$ Gráfico 1 apresenta a evolução do EGI para essas indústrias (CNAE-16, CNAE-19, CNAE-32, CNAE-35).

17 Com base na Pesquisa Industrial Anual - Empresa do IBGE, ano de 2007 a 2014.

18 Segundo a matriz de insumo-produto do IBGE do ano 2005, o setor de serviços de alojamento e alimentação é o setor com o maior coeficiente técnico como demandante da indústria de Alimentos e Bebidas, e o setor agrícola, o maior enquanto fornecedor de insumos à indústria. 
A indústria de Fumo, a mais concentrada do país no ano de 2002 (EGI 0,152), manteve-se com um alto nível de concentração em todo o período de análise, mas com uma tendência para desconcentração (o EGI caiu $27 \%$ ). No ranking estabelecido para as indústrias da transformação por Vignandi et al. (2014), a partir do EGI ponderado espacialmente, a indústria do Fumo ficou na segunda colocação, tanto no ano de 1995, quanto em 2010.

\section{Gráfico 1 Evolução do EGI das divisões com o índice acima de 0,05 em pelo menos um Ano (2002 a 2014)}

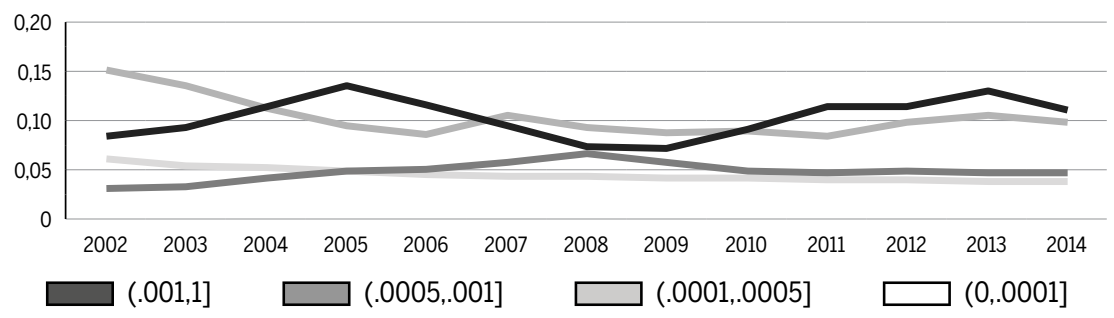

Fonte: Microdados RAIS-ME.

\section{Indústria de Fumo (Divisão 16)}

Essa indústria é composta por dois tipos de produção, o processamento industrial do fumo e a fabricação de produtos finais para consumo, como os cigarros. Intensiva em recursos naturais, as primeiras devem se localizar nas regiões que apresentem as condições climáticas e geográficas favoráveis ao cultivo do fumo, e a produção final dos cigarros, naquelas com melhor acesso ao mercado consumidor. No país, a maior parte dos estabelecimentos de beneficiamentos do fumo está concentrada na região Sul do país, que segundo a Confederação Nacional das Indústrias (CNI) ${ }^{19}$ responde por $97 \%$ da produção nacional do fumo. Porém, ainda segundo a CNI, a Região Sudeste do país é um importante centro de distribuição dos produtos, como cigarros e afins, para o resto do país e exterior. Acredita-se que as políticas nacionais de controle ao tabaco ${ }^{20}$ que vêm sendo

19 Consultar:<http://www.portaldaindustria.com.br/cni/canais/brazil-4-business/industriado-fumo/>.

20 A Política Nacional de Controle ao Tabaco busca atingir toda a sociedade, os envolvidos diretamente na sua produção, os consumidores e demais cidadãos, com ações e programas de 
adotadas na região Sul do país para a diversificação da produção agrícola do Tabaco ${ }^{21}$ deve ter contribuído, em parte, para a queda do nível de concentração da indústria, ${ }^{22}$ já que esta é a principal produtora dos produtos derivados do fumo.

Figura 2 Distribuição espacial da participação relativa do emprego na indústria do Fumo por microrregiões do Brasil em 2002 e 2014

2002

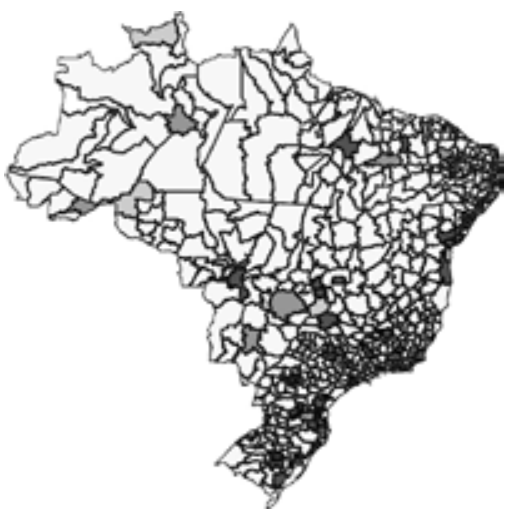

$\square(.001,1]$

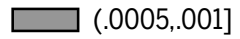

$(.0005, .001]$

$\square(.0001, .0005]$ 2014

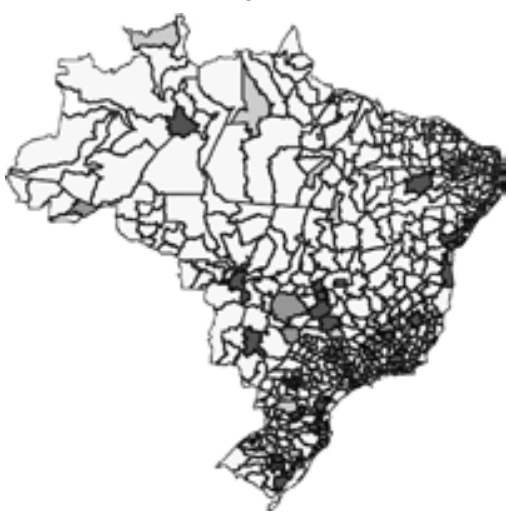

$(0, .0001]$

Fonte: Elaboração própria a partir dos microdados da RAIS-ME (2002-2014).

\section{Indústria de Produtos de Couros (Divisão 19)}

Essa indústria manteve-se com um EGI acima da média de todas as divisões da indústria da transformação, para o período analisado, e em um nível próximo à faixa de alta concentração. Destaca-se, porém, que o EGI da indústria apresentou contínua tendência de decréscimo, caiu $38 \%$, entre o ano de 2002 (EGI 0,064) e o ano de 2014 (EGI 0,038). No Brasil, essa indústria é intensiva em mão de obra e encontra-se localizada em quase controle ao tabaco. Para mais informações consultar:<http://www2.inca.gov.br/wps/wcm/ connect/observatorio_controle_tabaco/site/status_politica/a_politica_nacional>.

21 Como exemplo cita-se o Programa Nacional de Fortalecimento da Agricultura Familiar (Pronaf) para diversificação de atividades por agricultores que produzem tabaco.

22 Para mais informações consultar: <http://www.mda.gov.br/sitemda/noticias/mda-apresenta-estrat \%C3\%A9gia-para-diversifica \%C3\%A7\%C3\%A3o-do-tabaco>. 
todo o litoral do país e em algumas microrregiões interioranas, nas áreas rurais ligadas à pecuária (ver Figura 3).

Ela é caracterizada por uma grande participação de micro e pequenas empresas ( $90 \%$ dos estabelecimentos). A esse fato, adiciona-se que apenas 10 microrregiões do país, com as maiores participações relativas no emprego da indústria, responderam por $61 \%$ do emprego gerado por essa indústria, no ano de 2002, reduzindo para 54\%, no ano de 2014. Essa queda deveu-se, em parte, à perda da importância relativa da principal produtora do país, a microrregião de Porto Alegre (RS): sua participação no emprego da indústria caiu 38\%, em relação ao ano de 2002 (passou de $20 \%$ para $12,5 \%$, entre 2002 e 2014). Por outro lado, microrregiões do interior do país, com participações menos expressiva no emprego da indústria, como Divinópolis (MG), Sobral (CE), Pacajus (CE), Cariri (CE) e Campina Grande $\mathrm{PB})$, cresceram em importância, com destaque para Sobral, que foi a quinta microrregião que mais gerou emprego na indústria (5\%) no ano de 2014.

Figura 3 Distribuição espacial da participação relativa do emprego na indústria de Couro por microrregiões do Brasil em 2002 e 2014
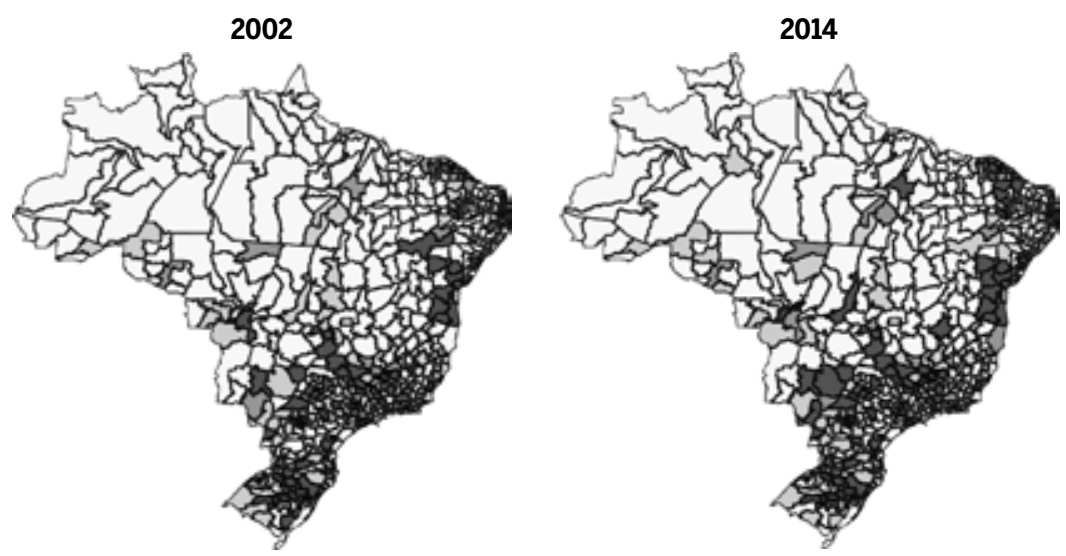

$\square(.001,1]$

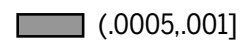

$\square(.0001, .0005]$

$(0, .0001]$

Fonte: Elaboração própria a partir dos microdados da RAIS-ME (2002-2014).

Adicionam-se a essas constatações, as principais características da indústria: de acordo com os dados da RAIS-ME, em torno de $50 \%$ do seu pessoal ocupado são trabalhadores polivalentes da confecção de calçados 
(CBO 7640), preparação da confecção de calçados (CBO 7641), e operadores de máquinas de costurar e montar calçados (CBO 7642), que possuem baixa escolaridade, mas desenvolvem atividades manuais que requerem habilidades técnicas específicas que se aprendem na prática da atividade. Por todos esses fatores, acredita-se que está havendo o deslocamento dessas indústrias para o nordeste do país, em especial, para as localidades que já desenvolviam atividades que requeriam habilidades compatíveis com a indústria de Couro, como aquelas necessárias na indústria têxtil e de confecção. Santos et al. (2002) em estudo específico sobre o deslocamento das empresas sulinas da indústria calçadista para os estados do Ceará e da Bahia constataram que os principais fatores que originaram esse movimento foram: a busca por maior competitividade, derivado de menores custos de produção; e maior participação no mercado internacional devido à maior proximidade com os principais países consumidores.

\section{Indústria de Fabricação de Material Eletrônico e de Comunicações (Divisão 32)}

Essa Indústria, de alta intensidade tecnológica, é uma das mais concentradas no país. No ano de 2005, chegou a ser a primeira colocada no ranking do EGI (índice de 0,14). Nesse ano, também houve expressivo crescimento na participação relativa da microrregião de Manaus (AM) no emprego gerado pela indústria, que passou de $29 \%$ (no ano de 2002) para $38 \%$ (no ano de 2005). Ressalta-se, porém, que a microrregião de Manaus é beneficiada por uma política de incentivos fiscais desde a década de 1960, conhecido como Zona Franca de Manaus. ${ }^{23}$ A partir do ano de 2005, a indústria se tornou menos concentrada, atingindo os seus menores EGI, em torno de 0,07, nos anos de 2008 e 2009. Essa tendência de desconcentração da indústria foi acompanhada pela redução da participação da microrregião de Manaus no emprego gerado pela indústria, que caiu $12 \%$, entre o ano de 2005 e 2009. Destaca-se que, nesse período, o país passou por uma crise econômica que implicou a queda do consumo de seus produtos e, conse-

23 A Zona Franca de Manaus, uma área de livre-comércio da Amazônia, surgiu como uma política de desenvolvimento regional, com o objetivo de tornar a região um importante polo comercial e industrial do país. Para detalhes sobre a Zona Franca de Manaus consultar: < http://www.suframa.gov.br/zfm_historia.cfm>. 
quentemente, houve redução na produção de alguns produtos eletrônicos, especialmente celulares e motocicletas. ${ }^{24}$

No Brasil, há dois principais polos da indústria, um na Região Norte, com destaque para a microrregião de Manaus, e o outro no tradicional polo tecnológico do país, no estado de São Paulo, mais especificamente nas microrregiões de São Paulo (SP), Campinas (SP) e São José dos Campos (SP). Apenas essas quatro microrregiões concentraram mais de $50 \%$ do emprego gerado pela indústria ( $63 \%$ no ano de 2002 e $56 \%$ no ano de 2014). A indústria por ser intensiva em tecnologia e por produzir insumos utilizados por outras indústrias, além de bens de consumo duráveis, deve se localizar naquelas microrregiões que possuem infraestrutura tecnológica, além de mão de obra especializada (Thisse, 2018). Por isso, percebe-se que essa indústria está concentrada exatamente nas localidades onde há aglomerações de outras indústrias que se inter-relacionam na sua cadeia produtiva, como é o caso da indústria de Fabricação de Aeronaves (CNAE 35) em São José dos Campos.

Figura 4 Distribuição espacial da participação relativa do emprego da indústria de Máquinas e Equipamentos por microrregiões do Brasil em 2002 e 2014
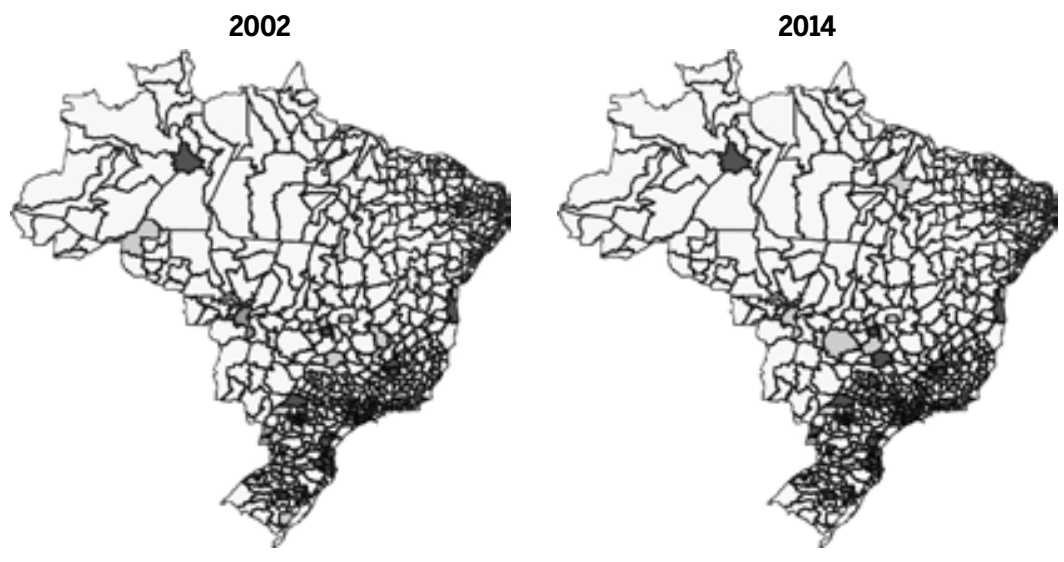

$\square(.001,1]$

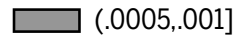

$\square(.0001, .0005]$

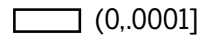

Fonte: Elaboração própria a partir dos microdados da RAIS-ME (2002-2014).

24 Oliveira (2011) apresenta dados sobre o desempenho da indústria na Zona Franca de Manaus. 
Através da Figura 4, pode-se visualizar as mudanças nas participações relativas das microrregiões no emprego gerado pela indústria, entre os anos de 2002 e 2014, com o aumento da participação de algumas microrregiões do Centro-Sul do país. Nesse sentido, destaca-se a perda expressiva da importância da microrregião São Paulo no emprego da indústria, que reduziu quase pela metade entre o ano de 2002 e 2014 (passou de 17\% para 8\%). Essa evidência é condicente com outros estudos já realizados para o país, os quais destacam o crescimento da indústria nas cidades de médio porte no interior do país (Costa; Biderman, 2016), especialmente no estado de São Paulo - naquelas cidades que possuem infraestrutura compatível para o desenvolvimento da indústria e ainda apresentam menor custo de produção em relação aos grandes centros urbanos.

\section{Indústria da Fabricação de outros Equipamentos de Transporte (Divisão 35)}

Essa indústria é intensiva em tecnologia e fabrica veículos de transporte não automotores, como a construção/montagem/reparação de embarcações, veículos ferroviários e aeronaves. Essa indústria esteve entre as cinco mais concentradas no país e, entre o ano de 2002 e o ano de 2008, o seu EGI mais que duplicou (passou de 0,031 para 0,07). Após o ano de 2008, percebe-se certa queda no nível de concentração da indústria, que atingiu o patamar de 0,05 no ano de 2014.

Pelo fato de produzir bens de alto valor agregado, intensivos em tecnologia, e de grande dimensão, ela deve se concentrar nas microrregiões com maior importância em geração de ciência e tecnologia, que têm infraestrutura compatível para o seu desenvolvimento, além de mão de obra qualificada. De fato, no ano de 2002, apenas a microrregião de São José dos Campos (SP), onde está localizado um importante parque tecnológico do país e importantes intuições de educação e pesquisa, ${ }^{25}$ respondeu por um quarto do emprego gerado pela indústria, e sua principal atividade era a Construção/Montagem/Reparação de Aeronaves. No ano de 2002, essa atividade foi a mais representativa em geração de emprego para a indústria

25 Entre as importantes instituições de ciência e tecnologia instaladas na microrregião São José dos Campos, estão o Instituto de Aeronáutica e Espaço (IAE) e o Instituto Tecnológico de Aeronáutica (ITA). 
(32\%). Porém, entre os anos de análise, houve uma mudança estrutural na indústria, a principal atividade passou a ser a construção de embarcações, que chegou a responder por 53\% do emprego da indústria (ano de 2014). Para exemplificar, destaca-se a microrregião de Rio de Janeiro, um tradicional polo da indústria naval do país, que se tornou nesse ano a microrregião de maior participação no emprego da indústria (20\%). Adiciona-se a estas evidências, que a política industrial de incentivos fiscais e financeiros do Governo Federal e da Petrobras para a construção de estaleiros em algumas cidades litorâneas do país, ${ }^{26}$ deve ter influenciado o aumento relativo do emprego nas atividades de construção de embarcações. E, como essas indústrias produzem bens de peso elevado e de grande dimensão, de transporte fluvial, os custos de transporte levam a indústria a se aglomerarem no litoral, nas cidades portuárias.

Figura 5 Distribuição espacial da participação relativa do emprego da indústria de Fabricação de outros Equipamentos de Transportes por microrregiões do Brasil em 2002 e 2014
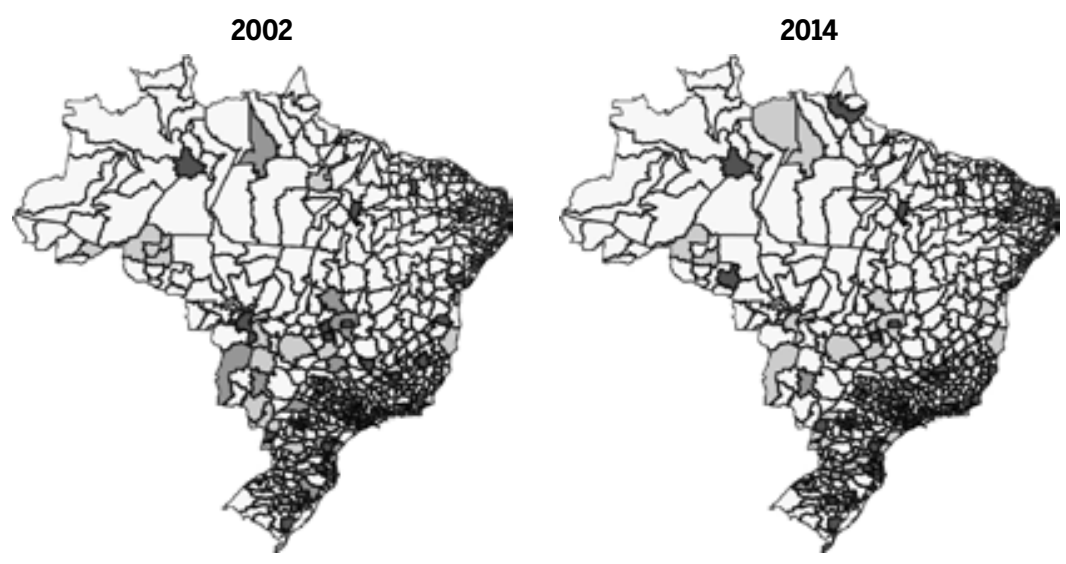

$(.001,1]$

$(.0005, .001]$

$\square(.0001, .0005]$

$(0, .0001]$

Fonte: Elaboração própria a partir dos microdados da RAIS-ME (2002-2014).

26 Citam-se, como exemplo, as políticas de incentivo à indústria Naval adotadas no período em análise: o Brasil Maior; o Programa de Modernização e Expansão da Frota de Navios Petroleiros da Transpetro (PROMEF) da Transpetro/Petrobras; e o Programa de Mobilização da Indústria Nacional de Petróleo e Gás Natural (PROMINP). (NETO et al., 2014). 
Através da Figura 5 percebem-se essas mudanças na distribuição do emprego da indústria, no sentido do litoral do país, que se destoa do padrão observado para toda a indústria da transformação, que tendeu a se concentrar mais distante do litoral (ver Figura 5).

\section{Considerações finais}

Com base em dois testes estatísticos, que têm respaldo em um modelo de escolha locacional proposto por Ellison e Glaeser (1997), esta pesquisa teve o seguinte objetivo: investigar se as indústrias da transformação do Brasil são concentradas espacialmente. Para tanto, calculou-se o EGI para as divisões das indústrias da transformação (2002 a 2014), a partir do qual apresentou-se uma análise da dinâmica da evolução do índice, com ênfase para aquelas indústrias que se mostraram mais concentradas.

Do conjunto dos resultados, destacam-se os principais. Primeiro, com base nos parâmetros de Ellison e Glaeser (1997), pode-se afirmar que a indústria da transformação no país é concentrada, mas tendeu a se desconcentrar no período de análise, corroborando a tendência evidenciada pela literatura citada no artigo para períodos anteriores. Segundo, os resultados indicaram que a indústria de Fabricação de Material Eletrônico/Comunicações (CNAE 32), intensiva em tecnologia, tornou-se mais concentrada; um movimento contrário as demais divisões de atividades, que apresentaram uma tendência média de queda ou estabilidade do EGI. Terceiro, dada a heterogeneidade das indústrias quanto ao tipo de bem produzido e à intensidade dos fatores de produção, o padrão da distribuição espacial as difere, sugerindo que os fatores locais, potenciais geradores de economias de aglomeração, atuam com diferentes magnitudes sobre a produtividade das indústrias. E, os resultados indicaram que essa desconcentração industrial no país foi acompanhada por uma mudança na distribuição espacial da indústria em direção ao interior do país, em especial para as microrregiões próximas do litoral, no centro-sul do país, que apresentam vantagens produtivas que devem compensar os seus custos de produção.

Esses resultados indicam que as vantagens locacionais, como o melhor acesso a infraestrutura tecnológica e mão de obra qualificada ou especia- 
lizada, devem ser consideradas em estudos que busquem explicar a concentração geográfica industrial no país e, em especial, daquelas indústrias intensivas em tecnologia. Ademais, destaca-se que a disponibilidade de mão de obra (labor pooling) a baixos custos também deve atuar como uma vantagem locacional, como no caso da indústria de Artefatos/Produtos de Couros (CNAE 19), uma das mais concentradas no país. Além disso, há de se reconhecer a importância das vantagens naturais, como a proximidade da costa marítima - mesmo perdendo importância enquanto força de atração das indústrias nas últimas décadas (a partir de 1990) -, que desempenha um papel relevante na explicação da geografia da distribuição geográfica de algumas indústrias no país.

Do outro lado, recomenda-se cautela nos estudos sobre economias de aglomeração e concentração geográfica das indústrias da transformação, dado que algumas indústrias que se mostraram mais concentradas também são beneficiadas por alguma política de incentivo fiscal regional. Nesse sentido, como proposta para trabalhos futuros, pretende-se expandir a análise, aplicando a decomposição de Dumais et al. (2002) ao índice de Ellison e Glaeser (1994), para explorar as fontes de variação do índice que explicam mais consistentemente as mudanças no seu nível.

\section{Referências}

ALMEIDA, Edilberto Tiago; ROCHA, Roberta de Moraes. Labor pooling as an agglomeration factor: Evidence from the Brazilian Northeast in the 2002-2014 period. EconomiA, v. 19, n. 2, p. 236-250, 2018.

BRITO, Adriana Fernandes; BONELLI, Régis. Políticas industriais descentralizadas: as experiências europeias e as iniciativas subnacionais no Brasil. Planejamento e Políticas Públicas, n. $15,2009$.

COSTA, Adriano Borges; BIDERMAN, Ciro. A dinâmica da concentração do emprego industrial no Brasil (1991-2011) e o ciclo de vida das empresas. ANPEC - Associação Nacional dos Centros de Pós-graduação em Economia [Brazilian Association of Graduate Programs in Economics], 2016.

DINIZ, Clélio Campolina. Desenvolvimento poligonal no Brasil: nem desconcentração, nem contínua polarização. Nova Economia, v. 3, n. 1, p. 35-64, 1993.

DINIZ, Clélio Campolina. A questão regional e as políticas governamentais no Brasil. Texto para discussão, v. 159, 2001.

DINIZ, Clélio Campolina; CROCCO, Marco Aurélio. Reestruturação econômica e impacto regional: o novo mapa da indústria brasileira. Nova Economia, 6, p. 77-103, 1996. 
DEVEREUX, Michael P.; GRIFFITH, Rachel; SIMPSON, Helen. The geographic distribution of production activity in the U K. Regional Science and Urban Economics, v. 34, n. 5, p.533-564, 2004.

DUMAIS, Guy; ELLISON, Glenn; GLAESER, Edward L. Geographic concentration as a dynamic process. The Review of Economics and Statistics, v. 84, n. 2, p. 193-204, 2002.

DURANTON, Gilles; OVERMAN, Henry G. Testing for localization using micro-geographic data. The Review of Economic Studies, v. 72, n. 4, p. 1077-1106, 2005.

ELLISON, Glenn; GLAESER, Edward L. Geographic Concentration in US Manufacturing Industries: A Dartboard Approach. NBER Working Paper No. 4840. 1994.

ELLISON, Glenn; GLAESER, Edward L. Geographic concentration in US manufacturing industries: a dartboard approach. Journal of Political Economy, v. 105, n. 5, p. 889-927, 1997.

FREITAS, Elton Eduardo; SIMÕES, Rodrigo Ferreira. Intensidade tecnológica e diferenciais regionais de produtividade: evidências de economias externas nas microrregiões brasileiras, 2000-2010. Artigo de divulgação científica. Confederação Nacional da Indústria (CNI), 2012.

FUJITA, Masahisa; THISSE, Jacques-François. Industrial agglomeration under Marshallian externalities. In Economics of agglomeration: Cities, industrial location, and regional growth. Cambridge University Press, Cambridge, 2002.

GALVAO, Olímpio. Clusters e distritos industriais: estudos de casos em países selecionados e implicações de política. Planejamento e Políticas Públicas, v. 21, p. 3-49, 2000.

HENDERSON, Vernon. Marshall's scale economies. Journal of urban economics, v. 53, n. 1, p. 1-28, 2003.

HIRSCHMAN, Albert. The strategy of economic development. New Haven: Yale University Press, 1958.

KRUGMAN, Paul. Increasing returns and economic geography. Journal of Political Economy, v. 99 , n. 3, p. 483-499, 1991.

LAUTERT, Vladimir; ARAÚJO, Nilton Clóvis Machado de. Concentração industrial no Brasil no período 1996-2001: uma análise por meio do índice de Ellison e Glaeser (1994). Economia Aplicada, v. 11, n. 3, p. 347-368, 2007.

LU, Jiangyong; TAO, Zhigang. Trends and determinants of China's industrial agglomeration. Journal of Urban Economics, v. 65, n. 2, p. 167-180, 2009.

MARSHALL, Alfred (1890). Principles of Economics: an introductory Princípios de Economia: tratado introdutório. São Paulo, SP: Abril Cultural, 1982.

MAUREL, Françoise; SÉDILLOT, Béatrice. A measure of the geographic concentration in French manufacturing industries. Regional Science and Urban Economics, v. 29, n. 5, p. 575 604, 1999.

MCFADDEN, Daniel. Conditional logit analysis of qualitative choice behavior. In Frontiers in Econometrics, ed. Zarembka P., New York Academic Press, 105-142, 1974.

MIRAGAYA, Júlio Flavio Gameiro. O desempenho da economia na Região Centro-Oeste. Um olhar territorial para o desenvolvimento: Centro-Oeste. Rio de Janeiro: Banco Nacional de Desenvolvimento Econômico e Social, 2014. 
MONTEIRO NETO, Aristides; GOMES, Gustavo Maia. Quatro décadas de crescimento econômico no Centro-Oeste brasileiro: recursos públicos em ação. Revista Econômica do Nordeste, Fortaleza, v. 30, n. Especial, 856-875, dez. 1999.

MYRDAL, Gunnar. Economic theory and under-developed regions. London Duck: Worth, 1957.

NETO, Campos; DA SILVA, Carlos Álvares; POMPERMAYER, Fabiano Mezadre. Ressurgimento da indústria naval no Brasil (2000-2013). 2014. Disponível em: <http://www. ipea.gov.br/agencia/images/stories/PDFs/livros/livros/livro_ressurg_da_ind_naval.pdf>, acesso em 04 de junho de 2019.

PACHECO, Carlos Américo. Novos padrões de localização industrial? Tendências recentes dos indicadores da produção e do investimento industrial. 1999.

RESENDE, Marcelo; WYLLIE, Ricardo. Aglomeração industrial no Brasil: um estudo empírico. Estudos Econômicos (São Paulo), v. 35, n. 3, p. 433-460, 2005.

ROCHA, Roberta de Moraes; BEZERRA, Fernanda Mendes; Soares, Cristiane de Mesquita. Uma Análise dos fatores de aglomeração da indústria de transformação brasileira. Revista Economia, 2013.

SANTOS, Ângela Maria Medeiros Martins et al. Deslocamento de empresas para os estados do Ceará e da Bahia: o caso da indústria calçadista. BNDES Setorial, Rio de Janeiro, n. 15, p. 63-82, mar. 2002.

SABOIA, João. Descentralização industrial no Brasil na década de noventa: um processo dinâmico e diferenciado regionalmente. Nova Economia, v. 11, n. 2, 2009.

SABOIA, João; KUBRUSLY, Lúcia Silva; BARROS, Amir Coelho. Caracterização e modificações no padrão regional de aglomeração industrial no Brasil no período 2003-2011. Pesquisa e Planejamento Econômico, v. 44, n. 3, dez, 2014.

THISSE, Jacques-François. Human Capital and Agglomeration Economies in Urban Development. The Developing Economies, v. 56, n. 2, p. 117-139, 2018.

VARGAS, Marco Antônio; OLIVEIRA, Bruno Ferreira de. Estratégias de diversificação em áreas de cultivo de tabaco no Vale do Rio Pardo: uma análise comparativa. Revista de Economia e Sociologia Rural, 2012, v. 50, n. 1, pp. 157-174.

VENABLES, Anthony. Localization of industry and trade performance. Oxford Review of Economic Policy, v. 12, n. 3, p. 52-60, 1996.

VIGNANDI, Rafaella Stradiotto; PARRÉ, José Luiz; DE FREITAS GUIMARÃES, Paulo. Concentração Industrial No Brasil: Uma Análise Espacialmente Ponderada. In: XLI Encontro Nacional de Economia. Anais, 2014.

\section{Sobre os autores}

Roberta de Moraes Rocha - roberta_rocha_pe@yahoo.com.br

Professora Associada da Universidade Federal de Pernambuco - Campus do Agreste (UFPE/CAA), Caruaru, Pernambuco,

Brasil.

ORCID: https://orcid.org/0000-0001-8111-7734.

José Ewerton Silva Araujo - joseewertonsa@gmail.com

Mestre em Economia pelo Programa de Pós-graduação em Economia (PPGECON) da Universidade Federal de

Pernambuco - Campus do Agreste (UFPE/CAA), Caruaru, Pernambuco, Brasil.

ORCID: https://orcid.org/0000-0001-6074-6208. 
Edilberto Tiago de Almeida - edilbertotiago@hotmail.com

Doutorando em Economia pelo Programa de Pós-graduação em Economia (PIMES) da Universidade Federal de Pernambuco, Recife, Pernambuco, Brasil.

ORCID: https://orcid.org/0000-0002-3965-6555.

Pesquisa realizada com apoio do Conselho Nacional de Desenvolvimento Científico e Tecnológico - CNPq

\section{Sobre 0 artigo}

Recebido em 24 de outubro de 2017. Aprovado em 19 de março de 2019. 


\section{APÊNDICE}

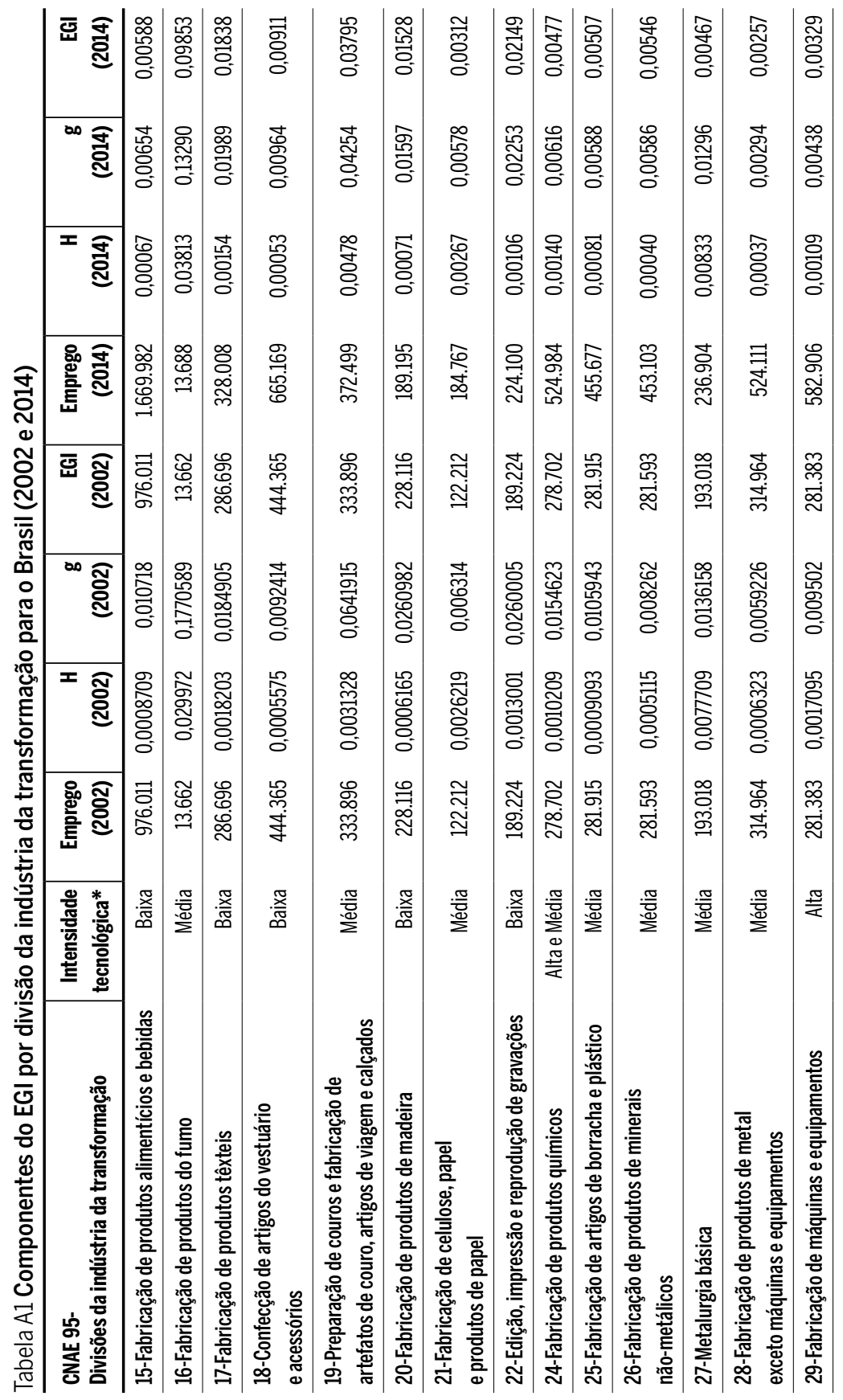




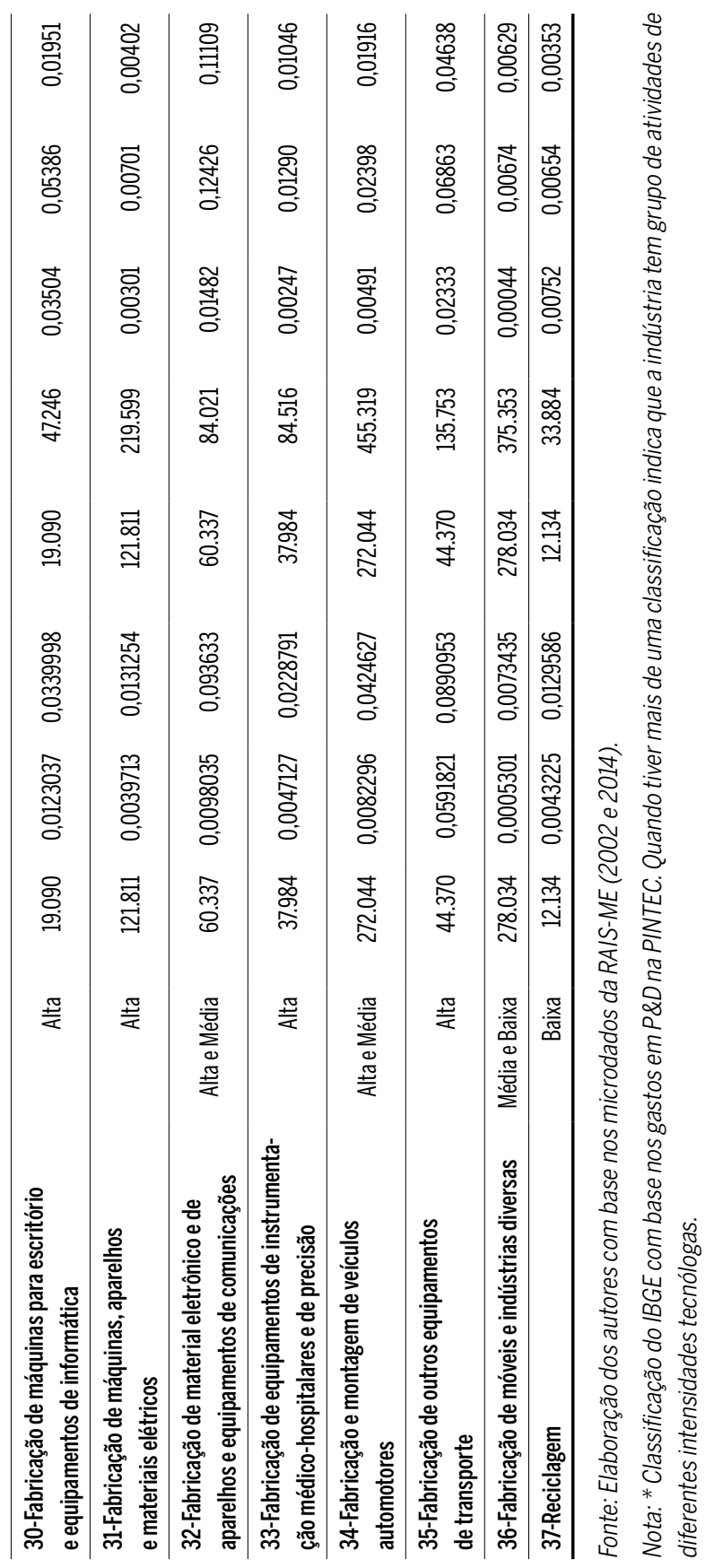

